\title{
CORRUPÇÃO E AS RODAS DO DESEMPENHO NO MERCOSUL
}

\author{
Lauro Vinício de Almeida Lima 1 \\ Maria Audenôra Rufino 2 \\ Paulo Amilton Maia Leite Filho ${ }^{3}$ \\ Márcia Reis Machado ${ }^{4}$
}

- Artigo recebido em: 29/01/2020 •- Artigo aceito em: 23/03/2020 -- Segunda versão aceita em: 06/07/2020

\section{RESUMO}

Com base na Teoria da Graxa sobre as Rodas, o estudo defende a possibilidade de a corrupção favorecer o desempenho econômico das empresas à medida que desate as amarras da burocracia e reduza os custos transacionais das empresas. Assim, a pesquisa teve como escopo investigar o reflexo da percepção da sociedade acerca da corrupção do setor público no desempenho econômico das empresas nos países do Mercosul. A amostra da pesquisa foi composta por 8 países integrantes do Mercosul, entre os anos de 2010 a 2017 , com um total de 667 empresas e 4.812 observações. Os dados foram estimados usando modelo de regressão em painel de efeitos fixos. A variável dependente foi à percepção de corrupção no setor público (IPC) e as variáveis independentes foram as medidas de desempenho ROE, ROA e EBIT. Os resultados encontrados conduzem ao entendimento que uma maior percepção da corrupção nos países do Mercosul aumenta o desempenho econômico das empresas naqueles países. As evidências empíricas encontradas acrescentam novas centelhas para 0 constructo argumentativo no qual se pauta a Teoria da Graxa sobre Rodas, com isto, fomenta-se fortes embates éticos, impondo uma ampla discussão sobre as políticas públicas de combate à corrupção no mundo e o prejuízo da corrupção para a sociedade, de forma sistêmica, sendo possível que estas consequências atinjam outros países ou blocos econômicos além do Mercosul.

1 Doutor pelo Programa de Pós-graduação em Ciências Contábeis - PPGCC/UFPB, Universidade Federal da Paraíba. Campus I, Cidade Universitária - João Pessoa/PB, Brasil. Email: Ivinicio2@gmail.com.

https://orcid.org/0000-0001-5474-5655

2 Doutoranda pelo Programa de Pós-graduação em Ciências Contábeis - PPGCC/UFPB, professora assistente da Universidade Federal de Sergipe. Campus Alberto Carvalho Itabaiana /SE, Brasil. E-mail: maryaudenora@hotmail.com.

https://orcid.org/0000-0001-7815-7831

3 Doutor em Economia pela Universidade Federal de Pernambuco, UFPE, Professor do PPGCC/UFPB, Universidade Federal da Paraíba. Campus I, Cidade Universitária - João Pessoa/PB, Brasil E-mail: pmaiaf@hotmail.com.

https://orcid.org/0000-0002-2471-3115

${ }_{4}$ Pós-Doutura em Educação Contábil pela Griffith University, Doutora em Ciências Contábeis pela USP, Professora Adjunta da UFPB - Universidade Federal da Paraíba. Campus I, Cidade Universitária - João Pessoa/PB, Brasil E-mail: marciareism@hotmail.com.

https://orcid.org/0000-0003-4081-6058

Editor responsável pela aprovação do artigo: Dr. João Estevão Barbosa Neto

Editora responsável pela edição do artigo: Drª Bruna Camargos Avelino 
Palavras-chave: Corrupção. Desempenho Econômico-financeiro. Teoria da graxa sobre rodas. Mercosul.

\title{
CORRUPTION AND PERFORMANCE WHEELS IN MERCOSUR
}

\begin{abstract}
Based on the Wheel Grease Theory, the study took into account the possibility that corruption may favor corporate economic performance as it unties the bureaucracy and reduces corporate transactional costs. Thus, the research was aimed at investigating, in Mercosur countries, the reflection of the society's perception about public sector corruption in the economic performance of companies. In a quantitative approach, the research sample consisted of 8 Mercosur member countries, between 2010 and 2017, with a total of 667 companies and 4,812 observations. Data were estimated using a fixed effects panel regression model. The dependent variable was the perception of corruption in the public sector (IPC) and the independent variables were the measures of ROE, ROA and EBIT performance. The results found lead to the understanding that a greater perception of corruption in Mercosur countries increases the economic performance of companies in those countries. The empirical evidence found adds new sparks to the argumentative construct in which the Wheel Grease Theory is guided, thereby fostering strong ethical struggles, imposing a broad discussion on public anti-corruption policies in the world, and corruption to society in a systemic way, and it is possible that these consequences hit other countries or economic blocs beyond Mercosur.
\end{abstract}

Keywords: Corruption. Performance. Economic-financial. Theory of grease on wheels. Mercosur.

\section{INTRODUÇÃO}

Os estudos, que discutem o lado maléfico da corrupção, explicam que os seus custos podem incluir a erosão de recursos críticos, como a reputação e a cultura das empresas, a alocação eficiente de recursos e a motivação para a inovação das empresas. Deste modo, a corrupção causaria desincentivo ao investimento adequado nas empresas para melhoria de sua produtividade, atuando, assim, como um limitante que prejudicaria o desempenho econômico das corporações (Vu, Tran, Nguyen, \& Lim, 2018).

Todavia, em que pese toda construção retórica acerca do lado negativo da corrupção, outros autores, como Aidt (2003), Vial e Hanoteau (2010), Dreher e Gassebner (2013) e Kato e Sato (2015), acreditam que a corrupção poderia atuar como uma "graxa sobre rodas" no mercado econômico. Sob esta perspectiva, apontam efeitos benéficos da corrupção, que seriam mais intensos em um ambiente onde as instituições públicas funcionam mal e o excesso de burocracia for um motivo limitante para a eficiência das empresas. De acordo com Lopes Júnior, Cãmara, Rocha e Brasil (2018), a corrupção pode, inclusive, ser desejada, em face de alguns aspectos relacionados à eficiência para o sistema - onde 
imperam a burocracia e a má governança das instituições públicas - como forma de dar velocidade às operações no mercado econômico.

Os efeitos positivos da corrupção discorridos nas pesquisas estariam relacionados como meio de contornar a ineficiência organizacional decorrente do excesso de normas e processos Kato e Sato (2015). Deste modo, a corrupção seria menos prejudicial à eficiência das empresas, em países onde as instituições públicas são menos eficazes, podendo apresentar associação positiva com a eficiência corporativa em países onde as instituições governamentais são extremamente ineficazes (Méon \& Weill, 2010).

Nesse baluarte, existem evidências empíricas que apontam um lado positivo da corrupção para empresas, como ocorreu na análise comparativa entre corrupção, crescimento e investimento, indicando uma relação positiva entre o crescimento e a corrupção em países do leste asiático, recentemente industrializados, como a China e a Indonésia (Rock \& Bonnett , 2004); assim como, a corrupção teria efeito positivo sobre o valor adicionado bruto por trabalhador e sobre a relação capital e mão de obra em setores de produção regulamentados na Índia (Kato \& Sato, 2015); também, ao verificar que a corrupção facilita a entrada de empresas em economias altamente reguladas (Dreher \& Gassebner, 2013); ou que a corrupção tem um efeito negativo direto sobre a probabilidade de uma empresa ser inovadora, mas um efeito positivo quando interage com obstáculos institucionais (Goedhuys, Mohnen, \& Taha, 2016).

Portanto, é possível que a corrupção permita que as empresas atinjam objetivos ou superem processos burocráticos e regulamentos pouco claros ou complexos. Como resultado, as empresas poderiam economizar tempo e conduzir atividades de negócios mais rapidamente ou "engraxar as rodas", o que pode promover o crescimento e melhorar 0 desempenho financeiro das empresas (Vial \& Hanoteau, 2010; Aidt, 2003).

Estende-se essas considerações a respeito do lado positivo e negativo da corrupção para os Países do Mercosul e em razão do World Economic Forum, em 2016 ter destacado a América Latina, do qual o Mercosul faz parte, uma região que apresenta alta percepção de corrupção pela sociedade. Dessa forma, alinhar as percepções de corrupção ao desempenho econômico em um local de alta corrupção, mostra-se oportuno à medida que pode contribuir para a ambiguidade de resultados presentes no campo disciplinar de pesquisa. Diante dos diversos argumentos teóricos que apoiam ambas as visões, negativas e positivas, sobre a corrupção, o presente estudo busca responder o seguinte questionamento: qual a influência da percepção da corrupção no setor público no desempenho econômico das empresas de capital aberto nos países do Mercosul?

O objetivo desta pesquisa é investigar a influência da percepção da corrupção no setor público no desempenho econômico das empresas de capital aberto do Mercosul. Os países do Mercosul foram escolhidos em razão da importância do bloco econômico para a economia mundial, sendo um bloco econômico composto por países em desenvolvimento, com singular convergência cultural e similaridade social, econômica e política. Neste contexto, a comparabilidade das empresas dentro do Mercosul é possível em razão da existência de uma zona de livre comércio, com união aduaneira e uma 
tarifa externa comum, permitindo um intenso relacionamento comercial entre os países integrantes do bloco, apoiado em um ideal de integração sul-americano plurissetorial e assegurado, juridicamente, por um Tribunal Arbitral Permanente. Assim, as empresas fixadas no Mercosul comungam das mesmas condições e oportunidades de negócios quanto ao seu desenvolvimento econômicofinanceiro frente ao resto do mundo.

O contributo teórico da pesquisa é expandir os limites dos estudos relacionados ao comportamento organizacional, ligados ao desempenho econômico, para trazer mais explicações sobre o ambiente empresarial nos blocos econômicos compostos por países em desenvolvimento diante da corrupção. Deste modo, ao revelar os efeitos da corrupção no desempenho econômico das empresas, à luz da Teoria da Graxa sobre Rodas, amplia-se a compreensão sobre o processo de tomada de decisão de alocação de recursos nas empresas em países que poderiam ser considerados arriscados, em função da percepção da corrupção no setor público pelos gestores e pela sociedade.

\section{PLATAFORMA TEÓRICA}

O interesse da comunidade científica pelo tema corrupção tem crescido ao longo das últimas décadas. Teoricamente, o efeito da corrupção sobre desempenho das empresas não pode ser explicado ou previsto por uma única teoria existente (Vu et al., 2018). As duas correntes teóricas mais utilizadas para explicar o efeito da corrupção sobre as organizações são (a) areia nas rodas Sand the Wheel - que critica a corrupção e busca evidenciar os obstáculos e prejuízos causados por ela; e (b) a graxa sobre rodas - Grease the Wheel - que apresenta os resultados benéficos que a corrupção possui na economia.

Ambas discutem a corrupção e a ineficiência da burocracia como dois motivos limitantes para o desenvolvimento econômico e o desempenho das organizações, porém a ineficiência da burocracia tem sido destacada, nas duas posições teóricas, como fator mais acentuado. Nesse sentido, o argumento da "graxa sobre rodas" insere-se como uma resposta à ineficiência burocrática, reduzindo o tempo gasto para atender os exigências normativas e os custos da lentidão.

A ideia mais preeminente sobre a relação entre a corrupção e o crescimento das empresas é que a relação é negativa, devido à instabilidade política e as relações curtas ou pontuais entre empresas e agentes. No entanto, algumas pesquisas defendem um efeito marginal positivo estatisticamente significativo de um aumento na corrupção sobre a eficiência em países governados temerariamente (Méon \& Weill, 2010). O argumento da "graxa sobre rodas" postula que uma burocracia ineficiente constitui um grande impedimento à atividade econômica e que alguma "velocidade" ou "graxa" pode ajudar a contornar esse impedimento (Aidt, 2003). Estudos testaram os benefícios e malefícios da corrupção em diversos cenários.

Vial e Hanoteau (2010), ao avaliarem o impacto da corrupção no nível da indústria e no crescimento da produtividade, descobriram que a corrupção, como subornos e pagamentos de impostos indiretos, tem um efeito positivo no crescimento individual das indústrias. Esse efeito persiste durante todo o período, o que sugere melhorias na eficácia do sistema de suborno e um fortalecimento 
do contrato de longo prazo entre as empresas e o governo. Kato e Sato (2015) investigaram se a corrupção "lubrifica as engrenagens" das burocracias e melhora o desempenho econômico. Os resultados das estimativas apontam para efeitos marginais significativamente positivos da corrupção, tanto no valor adicionado bruto por trabalhador como no índice de capital por mão-de-obra nos setores regulamentados.

Dreher e Gassebner (2013) investigaram se a corrupção pode "lubrificar as engrenagens" econômicas. Os resultados indicaram que a existência de um maior número de procedimentos necessários para iniciar um negócio, bem como maiores exigências de capital mínimo, são prejudiciais ao empreendedorismo; de forma que a corrupção reduz o impacto negativo das regulamentações sobre o empreendedorismo em economias altamente reguladas. Complementarmente, Goedhuys et al. (2016) exploraram o efeito dos obstáculos institucionais e da corrupção no comportamento inovador das empresas e seu efeito sobre o crescimento do emprego das empresas no Egito e da Tunísia. Os resultados conduzem para a compreensão que a corrupção tem um efeito negativo direto sobre a probabilidade de uma empresa ser inovadora, mas um efeito positivo quando interage com obstáculos institucionais. Isso fornece suporte para a hipótese de que a corrupção serve como um mecanismo para contornar os obstáculos burocráticos relacionados à obtenção das autorizações e licenças comerciais necessárias para a inovação de produtos.

\begin{tabular}{|c|c|c|}
\hline Estudos & $\begin{array}{l}\text { Local de } \\
\text { realização }\end{array}$ & Principais resultados \\
\hline $\begin{array}{l}\text { Méon e Weill } \\
(2010)\end{array}$ & $\begin{array}{l}\text { Dados de } 63 \text { a } 71 \\
\text { países entre } 1970 \text { e } \\
1998\end{array}$ & $\begin{array}{l}\text { Um efeito negativo da corrupção no crescimento } \\
\text { e no investimento. }\end{array}$ \\
\hline $\begin{array}{l}\text { Vial e } \\
\text { Hanoteau } \\
(2010)\end{array}$ & $\begin{array}{l}\text { Indonésia de } 1975 \\
\text { a } 1995 .\end{array}$ & $\begin{array}{l}\text { A corrupção, como subornos e pagamentos de } \\
\text { impostos indiretos, tem um efeito positivo no } \\
\text { crescimento individual das indústrias. }\end{array}$ \\
\hline $\begin{array}{l}\text { Kato e Sato } \\
(2015)\end{array}$ & $\begin{array}{l}\text { Índia de } 1988 \text { a } \\
1997 .\end{array}$ & $\begin{array}{l}\text { Aponta para efeitos marginais significativamente } \\
\text { positivos da corrupção. }\end{array}$ \\
\hline $\begin{array}{l}\text { Dreher e } \\
\text { Gassebner } \\
\text { (2013) }\end{array}$ & $\begin{array}{l}\text { Dados de } 43 \text { países } \\
\text { no período de } 2003 \\
\text { a } 2005 .\end{array}$ & $\begin{array}{l}\text { O maior numero de procedimentos é prejudicial ao } \\
\text { empreendedorismo. }\end{array}$ \\
\hline $\begin{array}{l}\text { Goedhuys et } \\
\text { al. (2016) }\end{array}$ & $\begin{array}{l}\text { Egito e Tunísia em } \\
2013 \text { e } 2014 .\end{array}$ & $\begin{array}{l}\text { A corrupção tem um efeito negativo direto sobre a } \\
\text { probabilidade de uma empresa ser inovadora. }\end{array}$ \\
\hline
\end{tabular}

Figura 1 - Resumo das pesquisas anteriores

Fonte: elaborado pelos autores

Portanto, diante dos argumentos conflitantes no sentido que a corrupção pode ser a areia sobre as engrenagens econômicas (negativo) ou a graxa sobre as suas rodas (positivo) e as disparidades entre as evidências encontradas nas pesquisas em várias partes do mundo, é importante aprofundar o estudo sobre o tema. Sobretudo porque o processo de tomada de decisão nas empresas sobre a alocação de recursos econômicos sopesam a exposição ao risco e o retorno sobre investimento, fazendo diferença nesta equação se o reflexo da corrupção pode trazer malefícios ou benefícios marginais para o desempenho econômico das empresas. 


\section{PROCEDIMENTOS METODOLÓGICOS}

\subsection{População e Amostra}

A pesquisa abrangeu as empresas de capital aberto dos países membros e associados do Mercosul. Os países que compuseram a amostra foram: Argentina, Bolívia, Brasil, Chile, Colômbia, Equador, Peru e Venezuela. Por falta de acessibilidade aos dados das empresas do Uruguai e Paraguai, estes países não foram incluídos na amostra. Também foram excluídas da amostra as empresas do setor financeiro e seguros, devido a regulamentação especial que se submetem e pela peculiaridade de sua estrutura de capital.

\subsection{Coleta de Dados}

As demonstrações contábeis das empresas, de 2010 a 2017, foram extraídas do banco de dados da Thomson Reuters Eikon ${ }^{\circledR}$, utilizando o dólar como moeda de referência. $O$ ano de 2010 foi escolhido porque entre 2008 e 2009 ocorreu uma crise financeira internacional desencadeada pela falência do banco americano Lehman Brothers, gerando um efeito cascata em outras instituições financeiras que quebraram, processo, este, que ficou conhecido como "crise dos subprimes" (Feldkircher, 2014). Esta crise financeira mundial pode ter afetado os resultados reportadas pelas empresas do Mercosul, com consequências no seu desempenho econômico-financeiro naquele período. As informações relativas aos índices de percepção da corrupção do setor público, por país e ano, foram coletados no site da Transparency International.

Assim, a Equação 1 foi utilizada para estimar a influência da percepção da corrupção no setor público no desempenho econômico das empresas dos países do Mercosul.

Desempenho $_{i t}=\alpha_{0}+\alpha_{1} I P C_{p t}+\alpha_{2} \operatorname{Rec}_{i t}+\alpha_{3}$ End $_{i t}+\alpha_{4} F C O_{i t}+\alpha_{5} \operatorname{Tam}_{i t}+\varepsilon$

Onde:

- Desempenhoit: é o desempenho econômico-financeiro da empresa i no tempo $t$, medido pelo retorno dos ativos (ROA), retorno sobre o patrimônio líquido (ROE) e o lucro operacional (EBIT);

- IPC pt: é o Índice de percepção da corrupção no setor público, calculado pela diferença entre 100 pontos e o índice de percepção divulgado pelo Transparency International, no país $p$ no período $t$, dividindo o resultado por 100, para que o entendimento do índice de percepção da corrupção seja analisado na escala de zero (altamente íntegro) a 1 (altamente corrupto);

- Recit: é a receita da empresa, calculado pela receita líquida da empresa i no período t sobre o ativo total no período t; 
- Endit: é o endividamento da empresa, calculado pelo total de capital de terceiros (passivo de curto e longo prazo) sobre o ativo total da empresa i no período t;

- FCOit: é o fluxo de caixa operacional, calculado pelo fluxo de caixa operacional da empresa i no período t sobre o ativo total no período t;

- Tamit: Tamanho da empresa, calculado pelo logaritmo natural do patrimônio líquido da empresa $i$ no período t;

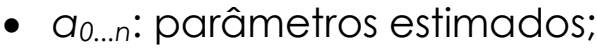

- $\varepsilon$ : são os resíduos da regressão.

Para mensurar o desempenho relacionado aos ativos investidos na empresa, foi utilizado o Retorno sobre os Ativos, Return On Asset (ROA). A opção pelo ROA recaiu pela sua capacidade de informar o quanto cada ativo gerou de retorno para o empreendimento, sendo utilizado, nas pesquisas, para avaliar o desempenho global, relacionado os lucros aos ativos disponíveis nas empresas (Barber \& Lyon, 1996; Ittner, Larcker, \& Rajan, 1997; Bonfim \& Callado, 2016).

Para a análise do desempenho do capital próprio foi utilizado o retorno sobre o patrimônio líquido, Return On Equity (ROE). Este indicador permite verificar o retorno proporcionado pelo investimento na empresa, sendo uma proxy frequentemente utilizado no mercado como medida de desempenho econômico das empresas (Barber \& Lyon, 1996; Bonfim \& Callado, 2016).

Para o desempenho operacional, utilizou-se o lucro antes dos encargos financeiros e impostos da empresa, Earnings Before Interest and Taxes (EBIT), sobre as suas receitas líquidas. A receita líquida é obtida pelo cálculo das receitas brutas abatidas das devoluções de vendas, descontos comerciais e impostos incidentes sobre as vendas. As receitas líquidas foram escolhidas para normalizar o efeito dos níveis de receitas das empresas e expurgar os efeitos dos tributos incidentes sobre as vendas. O EBIT, como medida de desempenho, foi escolhido por ser o lucro operacional obtido antes dos resultados financeiros e dos tributos sobre 0 resultado. Assim, expurga-se a influência direta das despesas com o endividamento e dos tributos sobre o resultado, traduzindo o reflexo dos custos transacionais incidentes nas atividades operacionais das empresas, sem o viés de eventuais reduções tributárias decorrentes de incentivos fiscais (Fortunato, Funchal, \& Motta, 2012; Bennet, Bettis, Gopalan, \& Milbourn, 2017).

O índice de percepção da Corrupção (IPC) divulgado pelo Transparency International mede níveis de percepção no setor público em todo o mundo, usando uma escala de zero (altamente corrupto) a 100 (altamente íntegro). Pela sistemática adotada no IPC, quanto maior o índice, menor o grau de corrupção. O IPC é uma proxy apropriada para medir a corrupção (Ribeiro, Pereira, \& Ribeiro, 2017; Mazzioni \& Klann, 2016; Zuccolotto \& Teixeira, 2014). Entretanto, visando simplificar o entendimento da análise dos resultados, nesta pesquisa, foi adotado o índice de forma inversa, em uma escala reduzida: zero (altamente íntegro) a 1 (altamente corrupto). Para tanto o índice de percepção da corrupção (IPC) foi calculada pela diferença entre 100 pontos e o índice de percepção divulgado pelo Transparency International, no país $p$ no período $t$, dividindo o resultado por 
100. Espera-se, pela teoria da graxa sobre rodas, que a variável IPC apresente uma relação positiva (direta) com o desempenho.

Para controlar os efeitos da corrupção no desempenho, utilizou-se a receita (Rec), porque qualquer desempenho econômico da empresa está intimamente relacionado com o nível de receita alcançado, sendo importante normalizar os dados utilizando o ativo total, em função da própria essência dos ativos, que para serem classificados como tal, precisam ter como natureza a expectativa de geração de fluxos de caixa futuros.

Do mesmo modo, utilizou-se no estudo o fluxo de caixa operacional (FCO), em razão do resultado galgado no desempenho econômico da empresa pode estar intimamente condicionado ao do fluxo de caixa operacional do período, relativizado pelo investimento realizado na empresa, e o endividamento (End), porque as dívidas onerosas da empresa podem interferir no desempenho das empresas, haja vista que os credores baseiam-se nos indicadores financeiroeconômicos das empresas para formulação de condições contratuais favoráveis, sendo possível, inclusive, que os gestores em manipularem as demonstrações contábeis para atender estas metas (Morsfield \& Tan, 2006).

Por fim, para controle da relação, também, foi utilizado o tamanho (Tam) das empresas, calculado pelo logaritmo natural do patrimônio líquido de cada empresa, porque a complexidade das demonstrações financeiras possui uma estreita relação com o tamanho (Watts \& Zimmermann, 1990).

Os dados utilizados na pesquisa foram trabalhados em um painel desbalanceado, visando ampliar ao máximo a quantidade de observações, referentes aos exercícios de 2010 a 2017. Utilizou-se as principais técnicas de dados em painel para verificação do modelo mais adequado para o tratamento dos dados, entre o modelo irrestrito pooled, o modelo restrito de efeitos fixos e o modelo restrito de efeitos aleatórios, por intermédio dos testes de Chow, Hausman e Breusch-Pagan. Também foram aplicados os testes de Wooldridge e Wald modificado para dados em painel para observar, respectivamente, a autocorrelação e a heterocedasticidade dos dados (Fávero, 2013).

\section{DESENVOLVIMENTO DA PESQUISA}

A amostra contendo 667 empresas, relativas aos 8 países do Mercosul, entre os anos de 2010 e 2017, está distribuída em 9 setores econômicos conforme a classificação do Thomson Reuters, consoante descrito na Tabela 1. 
Tabela 1

Descrição de Empresas por Setor Econômico

\begin{tabular}{l|c|c|c|c|c}
\multicolumn{1}{c}{ Setor Econômico } & Empresas & Observações & $\overline{\boldsymbol{R O A}}$ & $\overline{\boldsymbol{R O E}}$ & $\overline{\boldsymbol{E B I T}}$ \\
\hline Bens industriais & 125 & 818 & $29,27 \%$ & $6,35 \%$ & $11,40 \%$ \\
Comunicações & 19 & 116 & $29,52 \%$ & $6,53 \%$ & $3,98 \%$ \\
Consumo cíclico & 158 & 1026 & $29,65 \%$ & $8,39 \%$ & $4,98 \%$ \\
Consumo não cíclico & 173 & 1128 & $28,74 \%$ & $9,96 \%$ & $6,31 \%$ \\
Energia & 27 & 162 & $29,22 \%$ & $2,83 \%$ & $1,61 \%$ \\
Material básico & 148 & 964 & $29,69 \%$ & $11,20 \%$ & $6,10 \%$ \\
Saúde & 21 & 119 & $30,75 \%$ & $15,44 \%$ & $9,72 \%$ \\
Tecnologia & 12 & 77 & $32,57 \%$ & $10,91 \%$ & $7,97 \%$ \\
Utilidade & 116 & 768 & $30,24 \%$ & $12,05 \%$ & $7,07 \%$ \\
\hline TOTAL & $\mathbf{7 9 9}$ & $\mathbf{5 1 7 8}$ & $\mathbf{2 9 , 5 7 \%}$ & $\mathbf{1 0 , 2 6 \%}$ & $\mathbf{6 , 0 3 \%}$ \\
\hline
\end{tabular}

Nota: $\overline{\boldsymbol{R O A}}=$ média do Retorno sobre o Ativo Total das empresas da amostra; $\overline{\boldsymbol{R O E}}=$ média do retorno sobre o patrimônio líquido da empresa da amostra; $\overline{\boldsymbol{E B I T}}=$ média do lucro operacional da empresa da amostra.

Fonte: elaborado pelos autores

Conforme a Tabela 1 os setores da amostra que apresentaram maiores Retorno sobre os Ativos (ROA) foram os setores de Tecnologia (32,57\%) e Saúde $(30,75 \%)$. No tocante ao Retorno sobre o Patrimônio Líquido (ROE) foram os setores de Saúde (15,44\%) e de Utilidade (12,05\%). Já o Lucro Operacional (EBIT), os setores que apresentaram maior ponderação entre o lucro operacional sobre as receitas líquidas do período foram os setores de Bens industriais (1 1,40\%), seguido pelo de saúde $(9,72 \%)$.

Os setores que apresentaram menor desempenho foram Energia, com um ROE de 2,83\% e um EBIT de 1,61\%, e Consumo Não Cíclico, com um ROA de $28,74 \%$. O setor de energia é altamente regulamentado, com preços tarifados pelo governo, impedindo as empresas de estabelecerem os preços praticados consoante os seus custos e a demanda do mercado. Por se tratarem de serviços públicos essenciais e estratégicos, o governo, normalmente, determina os preços, pautados nos custos para a continuidade do serviço, com uma margem de retorno sobre o investimento em um patamar mínimo de atratividade. Portanto, esta é uma possível explicação baixo desempenho.

A Figura 2 apresenta o comportamento do desempenho econômico mediano das empresas ao longo período estudado. Consoante essa Figura, verifica-se um comportamento simétrico entre os índices de desempenho econômico utilizados, sendo que o ROA aparenta menor sensibilidade ao IPC, em comparação ao ROE e EBIT.

Em seguida, depreende-se, pela Figura 2, que as medidas de desempenho econômico tiveram uma queda entre 2010 a 2015. Neste período ocorreram intensas investigações sobre corrupção em diversos países do Mercosul, sobretudo no Brasil com a Operação Lava Jato, onde diversas empresas foram acusadas de beneficiar-se com "facilidades" do Governo em troca de "desvios para a corrupção". As investigações realizadas pela Operação Lava Jato, deflagrada em 2014, com reflexos em 2015, atingiram empresas brasileiras que mantinham negócios dentro e fora do Brasil, principalmente de outros países da América Latina, os quais, muitos, fazem parte do Mercosul. Também, verifica-se um crescimento do desempenho das empresas do Mercosul iniciado no ano de 
2016, provavelmente motivado pelo crescimento do Produto Interno Bruto (PIB), naquele ano, galgados pela Bolívia $(4,3 \%)$, Paraguai $(4,1 \%)$, Peru $(4 \%)$, Colômbia $(2 \%)$, Chile $(1,6 \%)$ e Uruguai $(1,5 \%)$, em sentido contrário da média da América Latina que sobre um decrescimento (-0,9\%) (Barría, 2017).

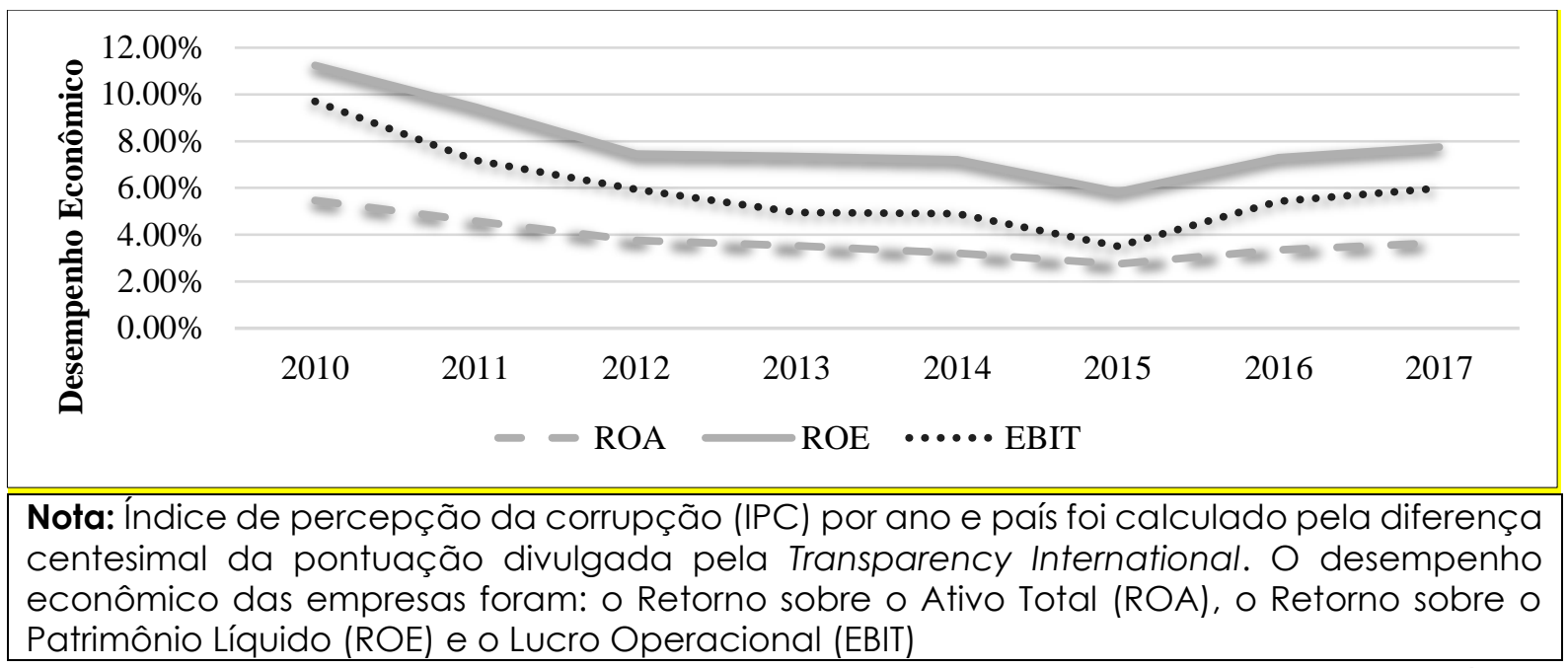

Figura 2 - Comportamento mediano do desempenho econômico das empresas nos países do Mercosul integrantes da amostra, durante os anos de 2010 a 2017.

Fonte: elaborado pelos autores

A Tabela 2 apresenta, acerca da amostra da pesquisa, a quantidade de empresas e observações por país no período observado. Consoante a essa Tabela, verifica-se que o Brasil e o Chile detém, juntos, mais da metade das observações da amostra. São dois países muito relevantes para o Mercosul, em razão do seu potencial econômico e demográfico. Já os países que possuem menor representatividade na amostra foram o Equador e a Bolívia, juntos, possuem menos de $4 \%$ do total de observações. Todavia, a inclusão destes países no estudo é de total relevância, à medida que traz mais informações para o estudo, permitindo estimar, de forma mais ampla e heterogênea, a influência da percepção de corrupção no desempenho das empresas atuantes nos países integrantes do Mercosul.

\section{Tabela 2}

Descrição de quantidade de empresas e observações por país na amostra

\begin{tabular}{l|c|c|c|l|c|c|c}
\hline País & Empresas & Obs. & $\mathbf{( \% )}$ & País & Empresas & Obs. & (\%) \\
\hline Argentina & 72 & 506 & 10,51 & Colômbia & 55 & 410 & 8,52 \\
Bolívia & 16 & 116 & 2,41 & Equador & 9 & 47 & 1 \\
Brasil & 238 & 1686 & 35,03 & Peru & 110 & 838 & 17,41 \\
Chile & 148 & 1091 & 22,67 & Venezuela & 19 & 118 & 2,45 \\
\hline
\end{tabular}

Fonte: elaborado pelos autores

A Figura 3 apresenta a pontuação divulgada pela Transparência Internacional, sendo pontuado 100 para um país altamente íntegro e 0 para altamente corrupto. De acordo com essa Figura, os três países do Mercosul que foram melhores posicionado em 2017, com a menor percepção de corrupção, no sentido da Transparency International, foram o Uruguai, Chile e Argentina. Os 
três países que obtiverem as piores posições foram Venezuela, Paraguai e Equador.

O índice divulgado pelo Transparency International usa uma escala de zero (altamente corrupto) a 100 (altamente íntegro), sendo construído por uma compilação de outros indicadores decorrentes de opiniões de pessoas ligadas a corporações transnacionais sobre o nível de corrupção que elas imaginam existir em um país. Em razão do público utilizado para captar a percepção da corrupção, o índice está pautado em opiniões de pessoas que possuem informações suficientes para aferir elementos burocráticos e os desvios de corrupção na concretização dos negócios no mercado de cada país e realizar uma comparabilidade entre eles.

Outrossim, nesta pesquisa, adota-se o índice de forma inversa, em uma escala reduzida: zero (altamente íntegro) a 1 (altamente corrupto). A opção pela inversão do índice decorreu da necessidade da pesquisa evidenciar o quantum a corrupção irá influenciar o desempenho, sendo necessário, portanto, que o índice utilizado refletisse a corrupção, propriamente dita, e não, a ausência dela, conforme utilizado na escala adotada pela Transparency International.

\section{Amêticas}
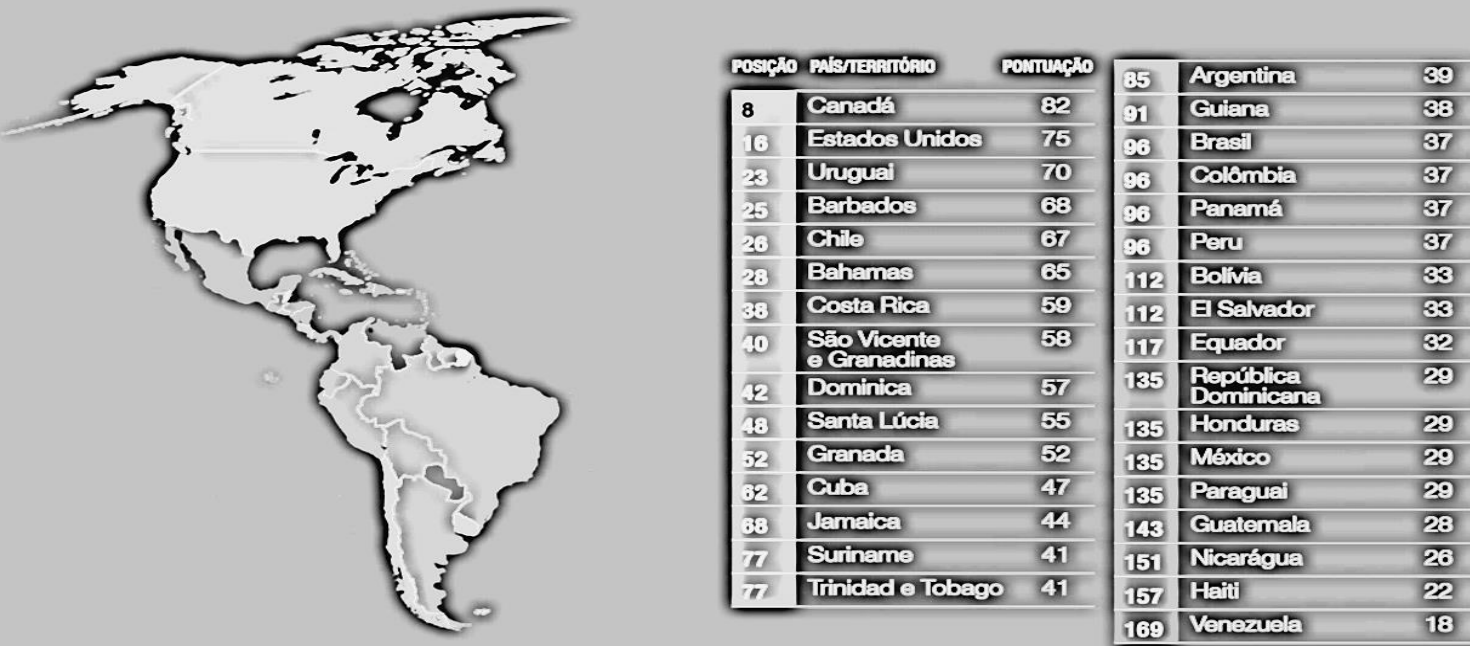

Figura 3 - Pontuação da percepção da corrupção em 2017 no continente americano e a posição de cada país com relação ao resto do mundo, de acordo com a Transparency Internatinal.

Fonte: Imagem extraída do relatório da Transparency International de 2017 divulgado no endereço eletrônico http://www.transparency.org/cpi. ISBN 978-3-96076-084-9

Em seguida, a Tabela 3 retrata a composição quantitativa e as estatísticas descritivas das variáveis contábeis calculadas para as empresas da amostra. 
Tabela 3

Estatística descritiva das empresas da amostra

\begin{tabular}{|c|c|c|c|c|c|}
\hline Variáveis & Média & Mediana & Desvio Padrão & Mínimo & Máximo \\
\hline ROA & 0,0395 & 0,3771 & 0,1123 & $-2,2650$ & 1,0547 \\
\hline ROE & 0,0691 & 0,7833 & 0,2212 & $-0,7963$ & 0,5819 \\
\hline EBIT & 0,0830 & 0,0572 & 0,1921 & $-0,3979$ & 0,7567 \\
\hline IPC & 0,5559 & 0,62 & 0,1432 & 0,27 & 0,83 \\
\hline $\operatorname{Rec}$ & 0,0704 & 0,0601 & 0,1833 & $-0,5094$ & 0,6129 \\
\hline End & 0,5113 & 0,5179 & 0,2155 & $-0,0608$ & 0,9989 \\
\hline $\mathrm{FCO}$ & 0,0695 & 0,6250 & 0,1047 & $-0,9329$ & 1,1825 \\
\hline Tam & 19,0090 & 19,1141 & 2,0099 & 10,5938 & 25,943 \\
\hline Empresas & & & 667 & & \\
\hline Observações & & & 4812 & & \\
\hline
\end{tabular}

Nota: As variáveis ROE, EBIT e Rec, foram winsorizadas em 0,05\%, em razão do alto desvio padrão encontrado, inicialmente, nos dados, sobretudo no setor de utilidade pública. Isso ocorreu porque os aportes sazonais de capital, existentes naquele setor, com a aquisição das concessões ou permissões para exploração dos serviços públicos, podem ter reflexos nas receitas e, por ricochete o EBIT. Do mesmo modo, o aporte sazonal de capital pode exercer uma influência no ROE, em razão de elevar o distanciamento proporcional entre o capital próprio e o capital de terceiros nas empresas.

Fonte: elaborado pelos autores

Verifica-se na Tabela 3 que a média do Retorno sobre os Ativos (ROA) foi de 3,95\%, do Retorno sobre o Patrimônio Líquido (ROE) foi de $6,91 \%$ e o Lucro Operacional Bruto sobre as receitas líquidas foi de 8,30\%. $O$ endividamento (End) foi de $51,13 \%$, as Receitas sobre os ativos (Rec) foi de $7,04 \%$, Fluxo de caixa Operacional (FCO) 6,95\% e o Tamanho das empresas (Tam) foi de 19,009. Quanto ao Índice de Percepção de Corrupção (IPC), a média do período ficou em 0,5559 .

A Tabela 4 traz a correlação de Kendall entre as variáveis da amostra utilizadas para estimar a Equação 1. A correlação de Kendall foi utilizada porque o comportamento das variáveis pode não ser linear, permitindo obter um coeficiente de correlação parcial, com o relaxamento dessa exigência (Bonett \& Wright, 2000).

Verifica-se, na Tabela 4, uma correlação positiva e significativa, ao nível de $1 \%$, entre o índice de percepção da corrupção (IPC) e todos os indicadores de desempenho econômico, ROA (4,07\%), ROE (2,62\%) e EBIT (3,88\%). As demais variáveis de controle, também apresentaram uma correlação significativa, ao nível de 1\%, com o desempenho, sendo, apenas, negativa a correlação entre o endividamento (End), o ROA e o EBIT. 
Tabela 4

Correlação de Kendall

\begin{tabular}{lllllllll}
\hline \multicolumn{1}{c}{ ROA } & ROE & EBIT & IPC & ReC & End & FCO & Tam \\
\hline IPC & $0,0407^{* * *}$ & $0,0262^{* * *}$ & $0,0388^{* * *}$ & 1 & & & & \\
ReC & $0,6818^{* * *}$ & $0,5849^{* * *}$ & $0,8771^{* * *}$ & $0,0246^{* * *}$ & 1 & & & \\
End & $-0,1546^{* * *}$ & $0,0236^{* *}$ & $-0,2305^{* *}$ & $-0,0251^{* * *}$ & $-0,2193$ & 1 & & \\
FCO & $0,3365^{* * *}$ & $0,3163^{* * *}$ & $0,2601^{* * *}$ & $-0,0077$ & $0,2590^{* * *}$ & $-0,0233^{* *}$ & 1 & \\
Tam & $0,0832^{* * *}$ & $0,1122^{* * *}$ & $0,1137^{* * *}$ & $-0,0810^{* * *}$ & $0,1300^{* * *}$ & $0,0766^{* * *}$ & $0,1471^{* * *}$ & 1 \\
\hline
\end{tabular}

Nota: ${ }^{* * *} / * *{ }^{*}$ sig. $>=1 \%, 5 \%$ e $10 \%$, respectivamente.

Fonte: elaborado pelos autores.

Por conseguinte, para medir a influência da percepção da corrupção no setor público no desempenho econômico nas empresas da amostra, recorreu-se ao modelo econométrico proposto na Equação 1, sendo, incialmente, realizado o teste de Chow, para comparar o modelo restrito (pooled) e o modelo irrestrito de efeitos fixos; o teste de Hausman, para verificação do melhor modelo, entre o de efeitos aleatórios e de efeitos fixos; e, enfim, o teste LM de Breusch-Pagan para comparação entre o modelo restrito e o modelo irrestrito de efeitos aleatórios (Clark \& Linzer, 2015). Pelos testes aplicados verificou-se que o melhor modelo para análise dos dados é o painel de efeitos fixos, conforme a Tabela 4.

Com o relaxamento do pressuposto da normalidade na distribuição dos dados, baseando-se no teorema do limite central, foram executados os exames de autocorrelação e homocedasticidade dos dados, não sendo encontrada, pelo teste de Wooldridge, em todos os modelos de desempenho a presença de autocorrelação. Todavia, pelo teste de Wald modificado para dados em painel, foi indicado heterocedasticidade dos dados, nos três modelos para estimação da influência da percepção de corrupção no desempenho (Wooldridge, 2002).

Ultrapassados todos os testes de pressupostos para estimação das regressões, foram estimadas as regressões, na forma robusta, utilizando os dados em painel balanceado e desbalanceado. A estimação de forma robusta consistiu em parâmetros estimados que levam em consideração a heterocedasticidade dos dados, em outras palavras, incorpora a heterocedastividade ao modelo. Os coeficientes encontrados, nas duas formas, induziram à mesma conclusão quanto a relação entre as variáveis de interesse e controle. Com isso, optou-se pelo o painel desbalanceado com o intuito de ampliar o número de observações e generalizar os parâmetros de forma mais abrangente. Os resultados obtidos com a estimação da Equação 1 encontra-se nas Tabela 5. 
Tabela 5

Estimação da regressão da Equação 1

\begin{tabular}{|c|c|c|c|c|c|c|}
\hline \multirow{2}{*}{ Variáveis } & \multicolumn{2}{|c|}{ ROA } & \multicolumn{2}{|c|}{ ROE } & \multicolumn{2}{|l|}{ EBIT } \\
\hline & Coeficientes & p-valor & Coeficientes & p-valor & Coeficientes & p-valor \\
\hline IPC & 0,0785 & 0,060 & 2,5203 & 0,022 & 0,1201 & 0,002 \\
\hline $\operatorname{Rec}$ & 0,3619 & 0,000 & 1,4557 & 0,000 & 0,9609 & 0,000 \\
\hline End & $-0,0437$ & 0,089 & 0,9719 & 0,246 & 0,0084 & 0,706 \\
\hline $\mathrm{FCO}$ & 0,2064 & 0,000 & 0,7772 & 0,156 & 0,0854 & 0,000 \\
\hline Tam & 0,0143 & 0,002 & 1,1863 & 0,005 & $-0,0004$ & 0,913 \\
\hline Intercepto & $-0,2928$ & 0,003 & $-24,6295$ & 0,004 & $-0,0530$ & 0,552 \\
\hline \multirow{2}{*}{$R^{2}$} & $\begin{array}{l}\text { Dentro } \\
0,4652\end{array}$ & $\begin{array}{l}\text { Entre } \\
0,3575\end{array}$ & $\begin{array}{l}\text { Dentro } \\
0,1045\end{array}$ & $\begin{array}{l}\text { Entre } \\
0,0318\end{array}$ & $\begin{array}{l}\text { Dentro } \\
0,8050\end{array}$ & $\begin{array}{l}\text { Entre } \\
0,8848\end{array}$ \\
\hline & \multicolumn{2}{|c|}{$\begin{array}{l}\text { Geral } \\
0,4323\end{array}$} & \multicolumn{2}{|c|}{$\begin{array}{l}\text { Geral } \\
0,0212\end{array}$} & \multicolumn{2}{|c|}{$\begin{array}{l}\text { Geral } \\
0,8466\end{array}$} \\
\hline Estatística F & \multicolumn{2}{|c|}{$\begin{array}{l}F(5,666)=77,71 \\
\text { Prob }>F=0,0000\end{array}$} & \multicolumn{2}{|c|}{$\begin{array}{l}F(5,666)=10,38 \\
\text { Prob }>F=0,0000\end{array}$} & \multicolumn{2}{|c|}{$\begin{array}{c}F(5,666)=972,33 \\
\text { Prob }>F=0,0000\end{array}$} \\
\hline VIF médio & \multicolumn{2}{|c|}{1,09} & \multicolumn{2}{|c|}{1,09} & & \\
\hline Modelo & Efeitos & ixos & Efeitos $\mathrm{F}$ & KOS & \multicolumn{2}{|c|}{ Efeitos Fixos } \\
\hline \multicolumn{3}{|c|}{ Quantidade de Empresas - 667} & \multicolumn{4}{|c|}{ Quantidade de Observações - 4812} \\
\hline Testes & Estatística & $p$-valor & Estatística & $p$-valor & Estatística & $p$-valor \\
\hline Chow & 4,65 & 0,0000 & 5,19 & 0,0000 & 2,44 & 0,0000 \\
\hline$\angle M B P$ & 800,36 & 0,0000 & 1193,69 & 0,0000 & 301,70 & 0,0000 \\
\hline Hausman & 112,54 & 0,0000 & 233,42 & 0,0000 & 30,55 & 0,0000 \\
\hline Wooldrigde & 0,036 & 0,8494 & 3,438 & 0,0641 & 11,734 & 0,0000 \\
\hline Wald & $1.3 e+07$ & 0,0000 & $1.3 e+07$ & 0,0000 & $7.9 e+29$ & 0,0000 \\
\hline
\end{tabular}

Nota: $\mathbf{R O A}=$ Retorno sobre $\circ$ Ativo Total da empresa $i$ no período $t ;$ ROE $=$ Retorno sobre 0 Patrimônio Líquido da empresa $i$ no período t; $\mathbf{E B I T}=$ Lucro Operacional da empresa sobre as receitas operacionais líquidas da empresa i no período t; IPC = índice de percepção da corrupção no setor público, calculado pela diferença entre 100 pontos e o índice de percepção divulgado pelo Transparency International, no país $p$ no período $t$, dividindo o resultado por 100, para que o entendimento do índice de percepção da corrupção no setor público seja analisado na escala de zero (altamente íntegro) a 1 (altamente corrupto) Diferença entre o Lucro Tributário e o Contábil da empresa $i$ no tempo † dividido pelo Ativo total do período $t-1 ; \operatorname{Rec}=$ Variação da receita líquida sobre o ativo total da empresa $i$ no período t; End $=$ Grau de endividamento, calculado pela divisão capital de terceiros sobre o ativo, da empresa $i$ no período t; FCO = Fluxo de Caixa Operacional sobre o ativo total da na empresa i no período t; e TAM = Logaritmo natural do patrimônio líquido da empresa i no período t.

Fonte: elaborado pelos autores

Na Tabela 5, observa-se que as relações encontradas entre a percepção de corrupção no setor público (IPC) e todas as medidas de desempenho foram positivas e significativas estatisticamente. A relação com o $\operatorname{ROA}(0,0785)$ apresentou significância ao nível de $10 \%$, o ROE $(2,5203)$, ao nível de 5\%, e o EBIT $(0,1201)$, ao nível de $1 \%$. Estas evidências coaduna-se com a teoria da graxa sobre rodas, sendo possível que a corrupção tenha favorecido o desempenho econômico das empresas do Mercosul, somando-se às conclusões encontradas por Aidt (2003), Vial e Hanoteau (2010), Dreher e Gassebner (2013) e Kato e Sato (2015) em outros estudos.

No tocante as variáveis de controle, com relação ao ROA, depreende-se que as receitas ( $\operatorname{Rec}$ ) apresentaram uma relação positiva $(0,3619)$ e significativa, ao nível de $1 \%$, enquanto o endividamento (End) apresentou uma relação negativa $(-0,1121)$ e significativa, no nível de $10 \%$, com o ROA. O aumento do receita incrementou o ROA e endividamento reduziu-o. Na relação entre dívida 
e ativo da empresa, este resultado é esperado, porque as empresas terão que pagar juros pelo endividamento, reduzindo o resultado operacional do período e, por consequência, o lucro líquido sobre os seus ativos. O fluxo de caixa operacional (FCO) teve uma relação positiva $(0,2064)$ e significativa, no nível de $1 \%$, com o ROA, indicando que o aumento do fluxo de caixa operacional da empresa no período eleva o retorno sobre os ativos da empresa. O tamanho (Tam) apresentou uma relação positiva $(0,0143)$ e significativa, no nível de $1 \%$, com o ROA, conforme esperado da relação entre as variáveis.

$\mathrm{Na}$ relação com o $\mathrm{ROE}$, as receitas (Rec) teve uma relação positiva $(1,4557)$ e significativa, no nível de $1 \%$, com o ROE, indicando que o aumento das receitas líquidas das empresas no período eleva o retorno sobre o capital próprio e o tamanho (Tam) apresentou uma relação positiva $(1,1863)$ e significativa, no nível de $1 \%$.

Quanto ao EBIT, as receitas (Rec) apresentaram uma relação positiva $(0,9609)$ e significativa, ao nível de $1 \%$, indicando que o aumento das receitas líquidas das empresas no período eleva o lucro operacional das empresas e o fluxo de caixa operacional (FCO) apresentou uma relação positiva $(0,0854)$ e significativa, ao nível de $1 \%$. Os resultados encontrados convergem com a literatura revisada (Watts \& Zimmermann, 1990).

\section{CONSIDERAÇÕES FINAIS}

Discutindo as Teorias da Graxa e Areia sobre as Rodas, a pesquisa levou em consideração que a corrupção poderia favorecer o desempenho econômico das empresas ao desatar as amarras da burocracia e reduzir os custos transacionais das empresas com o adimplemento de exigências da legislação. $O$ objetivo foi investigar a influência da percepção da corrupção no setor público no desempenho econômico das empresas de capital aberto do Mercosul. Assim, este artigo buscou contribuir para o aprofundamento dessa discussão, trazendo maior objetividade no avanço do debate sobre os efeitos da corrupção no desempenho econômico-financeiro das empresas.

No estudo foram destacados os argumentos conflitantes dos lados negativos e positivos sobre os estudos relacionados à corrupção e as diferentes evidências encontradas nas pesquisas em várias partes do mundo, elevando a importante do presente proposto, pela necessidade de compreensão do processo de tomada de decisão de investimentos nas empresas diante da corrupção e do risco que ela representa.

Em uma abordagem quantitativa, onde foram analisados os dados contábeis de empresas de capital aberto de 8 países do Mercosul, os achados da pesquisa sugerem que a redução ou elevação do índice de percepção de corrução do país reflete diretamente no desempenho das empresas atuantes em um ambiente econômico corrupto.

Ainda que possam persistir efeitos nocivos da corrupção para a sociedade e ao ambiente, como um todo - ante aos danos à imagem da empresa e falta de credibilidade no mercado, que poderiam resvalar, negativamente, no retorno da empresa - os resultados encontrados, conduzem ao entendimento que uma maior percepção da corrupção nos países do Mercosul aumenta o desempenho econômica das empresas naqueles países, 
porque a corrupção pode servir de subterfúgio para as empresas reduzirem os custos transacionais decorrentes das exigências normativas do país, de forma que a percepção da corrupção pela sociedade no setor público apresente uma relação positiva com o Retorno sobre os Ativos (ROA), Retorno sobre o Patrimônio Líquido (ROE) e o Lucro Operacional (EBIT).

As evidências empíricas encontradas na pesquisa conduzem para a validação do constructo argumentativo no qual se pauta a Teoria da Graxa sobre Rodas. Neste ponto, percebe-se a importância do estudo, diante dos fortes embates éticos que envolvem o tema e da necessidade de uma ampla discussão sobre as políticas públicas de combate à corrupção no Mundo. Destarte, com vistas nos reflexos da corrupção para as empresas, a economia e a sociedade, de forma sistêmica, é possível que os resultados encontrados nesta pesquisa, também, sejam verificados em outros países ou blocos econômicos além do Mercosul.

Como limitação da pesquisa aponta-se a utilização exclusiva de medidas de desempenho contábeis, não sendo consideradas as que envolvem variáveis de mercado, as quais poderiam ser afetadas pelo sentimento do investidor quanto a percepção da corrupção no setor público e nas empresas. Do mesmo modo, podem existir outras variáveis que possibilitem controlar melhor a relação estuda e que não foram inseridas na pesquisa.

Para estudos posteriores, indica-se a verificação da diferença entre os blocos econômicos quanto o efeito da percepção da corrupção no desempenho das empresas, haja vista que as peculiaridades culturais, sociais, políticas e econômicas entre os blocos econômicos poderiam afetar o resultado da relação. Ainda, sugere-se a análise, no desempenho das empresas, dos efeitos dos resultados divulgados de descobertas de casos de corrupção envolvendo as empresas e o setor público, como, por exemplo, o caso da Operação Lava Jato ocorrido no Brasil. Posto que escândalos de corrupção podem alterar a percepção da corrupção no setor público pela sociedade e o comportamento das empresas, visando preservar uma boa reputação. Acredita-se que discussões sobre os fatores que de alguma forma se associam e alimentam a corrupção constituem objetivos relevantes para futuras pesquisas; e como desestimular ou combater esses fatores a corrupção também constituem objetivos relevantes.

\section{REFERÊNCIAS}

Aidt, T. (2003). Economic analysis of corruption: A survey. Economic Jornal, 113(491), pp. 632-652. https://doi.org/10.1046/j.0013-0133.2003.00171.x

Barber, B. M., \& Lyon, J. D. (1996). Detecting abnormal operating performance: the empirical power and specification of test statististics. Journal of Financial Economics, 41 (3), 359-399. https://doi.org/10.1016/0304-405X(96)84701-5

Barría, C. (2017, Outubro 29). Como a Bolívia se tornou o país que mais cresce na América do Sul. BBC Mundo. Retrieved Maio 10, 2018, from https://www.bbc.com/portuguese/internacional-41753995 
Bennet, B., Bettis, J. C., Gopalan, R., \& Milbourn, T. (2017). Compensation goals and firm performance. Journal of Financial Economics, 124(2), pp. 307-330. https://doi.org/10.1016/j.jfineco.2017.01.010

Bonett, D. G., \& Wright, T. A. (2000). A. Sample size requirements for estimating Pearson, Kendall and Spearman correlations. Psychometrika, 65, pp. 23-28. https://doi.org/10.1007/BF02294183

Bonfim, E. T., \& Callado, A. L. (2016). Análise dos Efeitos Provocados pelas Operações de Fusões e Aquisições no Desempenho Econômico-Financeiro de Empresas Brasileiras. Contabilidade Vista \& Revista, $27(3)$, pp. 105-123.

Clark, T. S., \& Linzer, D. A. (2015). Should I use fixed or random effects? Political Science Research and Methods, 3(2), pp. 399-408.

Dreher, A., \& Gassebner, M. (2013). Greasing the wheels? The impact of regulations and corruption on firm entry. Public Choice, pp. 155, pp. 413-432. DOI 10.1007/s $11127-011-9871-2$

Fávero, L. P. (2013). Dados em painel em contabilidade e finanças: teoria e aplicação. BBR-Brazilian Business Review, 10(1), pp. 131-156.

Feldkircher, M. (2014). The determinants of vulnerability to the global financial crisis 2008 to 2009: Credit growth and other sources of risk. Journal of international $\begin{array}{llll}\text { Money and } \quad \text { Finance, } & \text { 43, } & \text { 19. }\end{array}$ https://doi.org/10.1016/j.jimonfin.2013.12.003

Fortunato, G., Funchal, B., \& Motta, A. P. (2012). Impacto dos Investimentos no Desempenho das Empresas Brasileiras. Revista de Administração Mackenzie, 13(4), pp. 75-98.

Goedhuys, M., Mohnen, P., \& Taha, T. (2016). Corruption, innovation and firm growth: firm-level evidence from Egypt and Tunisia. Eurasian Business Review, pp. Volume 6, Issue 3, 299-322. 10.1007/s40821-016-0062-4

Ittner, C. D., Larcker, D. F., \& Rajan, M. V. (1997). The choice of performance measures in annual bonus contracts. The Accounting Review, 72(2), pp. 231255. https://www.jstor.org/stable/248554

Kato, A., \& Sato, T. (2015). Greasing the wheels? The effect of corruption in. Canadian Journal of Development Studies, 36(4), pp. 459-483. https://doi.org/10.1080/02255189.2015.1026312

Lopes Júnior, E., Cãmara, S., Rocha, L., \& Brasil, A. (2018). Influência da Corrupção nos Gastos das Empresas Estatais. Revista de Administração Pública, pp. 52(4), pp. 695-711. http://dx.doi.org/10.1590/0034-7612173631

Mazzioni, S., \& Klann, R. (2016). Determinantes da qualidade da informação contábil no contexto internacional . Revista Contemporânea de 
Contabilidade, pp. 13(29), pp. 3-32. https://doi.org/10.5007/2175$8069.2016 \mathrm{v} 13 \mathrm{n} 29 \mathrm{p} 3$

Méon, P., \& Sekkat, K. (2005). Does corruption grease or sand the. Public Choice, pp. 122(1-2), pp. 69-97. https://doi.org/10.1007/s $11127-005-3988-0$

Méon, P.G., \& Weill, L. (2010). Is Corruption an Efficient Grease? World Development, pp. Volume 38, Issue 3, pp. 244-259. https://doi.org/10.1016/j.worlddev.2009.06.004

Morsfield, S. G., \& Tan, C. E. (2006). Do venture capitalists influence the decision to manage earnings in initial public offerings? Accounting Review, 81, pp. 1119 1150. https://doi.org/10.2308/accr.2006.81.5.1119

Ribeiro, R., Pereira, V., \& Ribeiro, K. (2017). Estrutura de Capital, Internacionalização e Países de Destino de Empresas Brasileiras: Uma Análise da Hipótese Upstream-Downstream. Brazilian Business Review, pp. 14(6), pp. 575-591.

Rock, M., \& Bonnett , H. (2004). The comparative politics of corruption: Accounting for the East Asian paradox in empirical studies of corruption,growth and investment. World Development, pp. 32(6), pp. 999-1017. https://doi.org/10.1016/j.worlddev.2003.12.002

Vial, V., \& Hanoteau, J. (2010). Corruption, manufacturing plant growth, and the Asian paradox: Indonesian evidence. World Development, pp. 38(5), pp. 693705. https://doi.org/10.1016/j.worlddev.2009.11.022

Vu, H., Tran, T., Nguyen, T., \& Lim, S. (2018). Corruption, Types of Corruption and Firm Financial Performance: New Evidence from a Transitional Economy. Journal of Business Ethics, pp. Abril, Volume 148, Issue 4, 847-858. https://doi.org/10.1007/s10551-016-3016-y

Watts, R. L., \& Zimmermann, J. L. (1990). Positive accounting theory: a ten-year perspective. 65(1), pp. 131-156. https://www.jstor.org/stable/247880

Wooldridge, J. M. (2002). Econometric analysis of cross section and panel data. Cambridge.

Zuccolotto, R., \& Teixeira, M. (2014). A efetividade dos institutos supremos de auditoria e dos legislativos na transparência fiscal. Revista de Contabilidade e Organizações, pp. 8(22), pp. 26-38. https://doi.org/10.11606/rco.v8i22.55608 
CONTRIBUIÇÕES DOS AUTORES

\begin{tabular}{|l|c|c|c|c|}
\hline \multicolumn{1}{|c|}{ Contribuição } & $\begin{array}{c}\text { Lauro Vinício } \\
\text { de Almeida } \\
\text { Lima }\end{array}$ & $\begin{array}{c}\text { Maria } \\
\text { Audenôra } \\
\text { Rufino }\end{array}$ & $\begin{array}{c}\text { Paulo } \\
\text { Amilton } \\
\text { Maia Leite } \\
\text { Filho }\end{array}$ & $\begin{array}{c}\text { Márcia Reis } \\
\text { Machado }\end{array}$ \\
\hline $\begin{array}{l}\text { 1. Idealização e concepção do } \\
\text { assunto e tema da pesquisa }\end{array}$ & $\checkmark$ & $\checkmark$ & & \\
\hline $\begin{array}{l}\text { 2. Definição do problema de } \\
\text { pesquisa }\end{array}$ & $\checkmark$ & $\checkmark$ & & \\
\hline $\begin{array}{l}\text { 3. Desenvolvimento da Plataforma } \\
\text { Teórica }\end{array}$ & & $\checkmark$ & & \\
\hline $\begin{array}{l}\text { 4. Delineamento da abordagem } \\
\text { metodológica da pesquisa }\end{array}$ & $\checkmark$ & $\checkmark$ & & \\
\hline 5. Coleta de dados & $\checkmark$ & $\checkmark$ & & \\
\hline $\begin{array}{l}\text { 6. Análises e interpretações dos } \\
\text { dados coletados }\end{array}$ & & & & \\
\hline 7. Conclusões da pesquisa & $\checkmark$ & & & \\
\hline 8. Revisão crítica do manuscrito & & $\checkmark$ & & \\
\hline $\begin{array}{l}\text { 9. Redação final do manuscrito, } \\
\text { conforme as normas estabelecidas } \\
\text { pela Revista. }\end{array}$ & & & $\checkmark$ & \\
\hline 10. Orientação & & & & \\
\hline
\end{tabular}

